\title{
Imitation as a Competitive Strategy
}

\author{
Kazimierz KRZAKIEWICZ and Piotr BARTKOWIAK* \\ Poznań University of Economics and Business, Poznań, Poland, kazimierz.krzakiewicz@ue.poznan.pl; \\ piotr.bartkowiak@ue.poznan.pl \\ * Corresponding author: piotr.bartkowiak@ue.poznan.pl
}

\begin{abstract}
Contemporary management faces the necessity of transformation, the result of which should be the survival and proper functioning of the organization. The source of transformation can be imitation, which is just as important in business as, for example, innovation, and a strategic approach to imitation is necessary for effective and efficient innovative activity. The study attempts to present the nature and role of imitation in building competitive advantages in firms. It is posited that in addition to being a recognised phenomenon in economic sciences imitation also underpins a number of competitive strategies followed by modern-day companies. Successfully resolving the problem of compliance with the imitation object ensures success for imitators. However, if this problem is not resolved and the follower does not obtain the expected benefits, significant disruptions in building strategic advantage arise, which in turn affect the costs and risk of the activity. Therefore, at the management level of the imitator, a control division should be created that allows to determine the mismatch between the organization's activities and the expectations of various stakeholder groups.
\end{abstract}

Keywords: imitation; innovation; competitive advantages; competitive strategy

JEL Classification: M11; O31; O39

\section{Introduction}

Contrary to some existing views on the nature of imitative processes which peg the latter as nothing more than copying that does not deserve deeper study, imitation activity in firms plays key roles in a market economy.

At the beginning of the 19th century, it took about a hundred years to copy a modern solution. In the years 1877-1930 the time of dissemination of imitated products was shortened to 23 years, in the following years 1930-1939 it was reduced to 9 years, and in 1940-1961 even to 5 years. In the 1980s, imitators only needed 12-18 months to develop an imitation. (Mansfeld, 1985, pp. 217-223; Krzakiewicz \& Cyfert, 2016b, p. 181)

The first to criticise the treatment of imitation was Israel Kirzner, a representative of the Austrian school of economics and a student of Ludwig von Mises. In his Competition and Entreprenership (1973) Kirzner addressed Schumpeter's classical view of entrepreneurship.

Kirzner noted that, as defined by Schumpeter, "entrepreneurship" is pursued by leaders innovators and market pioneers (first movers). It is clearly contrasted with the activity of numerous "copycats" following in the footsteps of entrepreneurs. The Kirznerian view is that, 
just like innovators, imitators, too, represent entrepreneurship. They take steps to exploit opportunities created as a result of the innovators' activity (Kirzner, 2010, p. 135).

It is exactly those numerous imitators - never relenting in their entrepreneurial alertness in pursuit of anything they might profitably use in their business (regardless of who developed or created it and when) - that set the market mechanism into motion. For all practical purposes, it is thanks to imitators that any innovation can materialise as far as is practicable. An increase in productivity can be noticed in business activity, because imitators can provide customers not only with a refined product, but also a much cheaper one. (Drucker, 2008) Therefore, it can be formulated that the most profitable innovations often have a large share of imitations. (Bayus et al., 2003, p. 198)

Firms imitate all the time. Nearly everything that is embraced as innovation (and often promoted as such through advertising campaigns) in reality builds extensively on the elements of imitation. Some Western experts in auditing innovative projects consider that only two percent of them are really innovative ventures. The rest are in fact imitations. They could involve major features of a product or just its small details; they could directly draw upon someone's experience, or they could result from product enhancement. The positive and negative consequences of changes in the organization in terms of imitation may be external and internal, relating to: 1) understanding and trust of employees; 2) flexibility of the organization and the ability to quickly adapt to the proposed changes, and consequently to achieve a competitive advantage; 3 ) recognition of the organization among all stakeholder groups; 4) the dynamics of changes, as a feature of the evaluation of the effectiveness of initiatives in the field of imitation introduced. (Jalagat, 2016, p. 1235)

In that regard, Kirzner posits that innovations and imitations are mutually complementary:

1. Innovation $=$ artificial, perfect phenomenon .

2. Innovation + imitation $=$ mass dissemination of innovations $/$ new solutions.

In reality, copying alone is just a specific case of imitation - one that does not fully encompass its essence or reflect all of its diverse forms. One could say that the stereotypical understanding of imitation as plain emulation hinders the development of a general theory of imitative processes.

In the new conditions of the organization's operation, imitations refer to an increasing number of products, services or business models, becoming more and more rational due to the costs incurred and potential profits. These realities transform the imitation into an important strategic factor taken into account in every organization, because "the days of great minds are over, now the effectiveness of the strategy requires a skillful imitation". (Krzakiewicz \& Cyfert, 2016a, p. 12)

\section{Imitation as a Source of Competitive Advantages}

The primary goal of imitation is to elicit information present in what is to be imitated and then use that information to achieve market success. A choice, a service, a technological 
process, a model, or a business strategy - all of these can be the object of imitation. (Krzakiewicz \& Cyfert, 2018b, p. 7)

Imitation presupposes underlying innovation. By definition, a market pioneer cannot be an imitator; after all, it has nothing to copy from. If a firm engages into copying, something must have already existed outside its organisation that the firm did not produce. In other words, imitation is not just copying but also involves dissemination and use of innovation where it has not been disseminated before.

Levitt has classified innovation by degree of their newness (Levitt, 2006, p. 2). The classification includes four kinds of innovation:

1. something that has never been done before;

2. something that has never been done in a given industry, although it is known by other industries;

3. something that is known by the industry, but has never been done in a given country;

4. something that has never been developed by the firm, although it is used by other firms from the same industry in a given country.

Except the last one, all of these cases involve an element of newness that is created for the first time (innovation). Also, except for the first one, all of them envisage a certain (different) amount of imitation. It is not by accident, therefore, that, looking at the relationship between the two, literature often examines "innovation" and "imitation" not as mutually exclusive terms but as ones that are placed along a sort of continuum, with full innovation at its one end, and full imitation at the other (Ethiraj, 2018). The latter means that all information the imitator has borrowed from the innovator as the sole source of knowledge underlying the copying process. (Krzakiewicz \& Cyfert, 2017, pp. 215-216)

Products in between those two extremes on a continuum are particularly interesting. In their case, the imitator has developed, obtained from the outside and/or integrated certain other knowledge resources in addition to whatever knowledge it has copied from the innovator. Generally, such products are characterised by how they differ from what would be pure imitation and innovation. Essentially, they remain a reflection of the innovator's product and are described as "creative imitation". Theodore Levitt calls it creative emulation (Levitt, 2006).

Creative imitation involves improving a product that is already on the market or adapting a product that exists in another industry. A company involved in this kind of imitation is called an imovator (IMitator + innOVATOR). For an imovator, imitation is not an alternative and innovative strategy; rather, it crucially complements such strategy, ensuring the imovator's competitiveness.

As it moves along the continuum towards its "pure innovation" extreme, innovativeness is increasing in its degree, as are its ordinary costs and the degree of risk involved. Where breakthrough innovation requires substantial expenditure and is not hedged against failure, imitation will always be less costly and its inherent risk can be determined relatively easily.

Generally, as innovativeness increases, so should a product's potential market success (specifically, this might be reflected in its increasing sales and/or profits). If successful, 
breakthrough innovation should bring huge benefits to the company that brought it on the market. That being said, one should remember that the more innovative a product is, the larger the risk involved, and not just potential success. For this reason, the expected effect will be gradually heading downwards on a growth curve: the potential for return on investment in solutions which are too revolutionary is limited by the higher risk. If events unfold according to this scenario (and while there are exceptions, it is a typical one) the maximum net result (that is, the difference between the expected effect and the expenditure) will not be achieved through high innovativeness alone. (Krzakiewicz \& Cyfert, 2019, pp. 5556)

From this perspective, it is easy to explain why it is often the case that an imitator turns out to be more effective than an innovator. The simple pattern also explains the main source of competitive imitation strategies: by spending substantially less than the innovator, an imitator will often earn at least the same revenue as the market pioneer.

It should also be emphasised that what generally leads to a positive outcome is creative rather than pure imitation. This is not surprising. A complete copy of an existing product has no significant advantages over it; indeed, it comes with a number of weak points, such as the product or its manufacturing technology being underdeveloped; being in the dark about the confidential know-how, lacking market reputation, operating a poor sales network, etc. This means that, generally, the pure imitator has to compete in what are clearly unfavourable conditions, often relying only on the impact of its lower product price.

With creative imitation, things are different. Firstly, the imitator often faces no competition at all. By adapting a known product and making its own version for the new industry, application or new national market, the imovator acts as a pioneer. Secondly, even if there is any direct market competition between the original and its modified copy, the original does not always have the competitive advantage. This is because the purpose of the adaptation process was to enhance some specific characteristics of the original

\section{Competitive Processes in New Product Evolution}

In most cases, when they are introduced on the market, products from pioneers are merely the first versions of what their customers expect. While there is potential in their newness, such products usually come with a number of deficiencies, hampering their development rather than giving the pioneer competitive advantage. The pioneer fails to gain the expected benefits and is forced to settle for the symbolic recognition of its mark it has left on the history of manufacturing or industry development. At the same time, a number of opportunities arise for those who follow the strategy of imitation.

Radical innovations are what especially drives product demand. For that reason, the inventors' goals need not be overly precise. Indeed, most new products out there turn out to be experimental and their consumers or users can only develop their preferences when using them. This has the following practical consequences: 
1. If a new product fails to meet what is a clearly stated need, it will generally take a long time before customers embrace it, which means that one should expect product acceptance to be slow.

2. If clearly stated needs are hard to discern, it will be impossible to establish with clarity which new product variant will be appropriate. In practice, one should expect the market to become quickly flooded with different product types, all created based on what entrepreneurs predict to be what their customers really expect. (Krzakiewicz \& Cyfert, 2018a, pp. 7)

In general terms, when they appear, the different innovations create some chaos. A wide range of competing product variants pops up, all having different performance characteristics and targeted towards different customer groups (although no special efforts are made in the targeting process). While the market becomes flooded with creative imitators, it is unclear for a long time which new features that were added to the original idea will hit "the bull's eye".

It is often the case that pioneers leave the market before sustained demand is created for their product. After the initial version of what was a successful product in the past failed to take off commercially, the pioneer may exit the market or indeed even go bust. In any such case, the future player that picks up the discarded idea will be considered an innovator, while what it did in fact was to copy that idea.

There might even be a few generations of unsuccessful pioneers. This was exactly the fate of a mobile phone, for which no competitive model could be successfully created for decades, even though how this new device functioned had been long known (this was the classic "devil is in the detail" situation).

Mobile phones are not an exception. There are numerous well-known products with a long wait time between their market launch and acceptance (e.g. $35 \mathrm{~mm}$ cameras - 40 years, microwave ovens -20 years; videogames -13 years; videocassette recorders -13 years; credit cards -8 years; ballpoint pens -8 years). Also, it is not always the first innovator that enjoys commercial success. For example, it is hard to determine how many generations of pioneers have changed during the 40 years before the $35 \mathrm{~mm}$ camera gained its market recognition.

Imitation at this stage in a product lifecycle has a specific character: imitators joint the business venture when even the pioneer is unable to generate profit. In practical terms, the imitator is a copycat only in a narrow technical sense: it has copied what was the essence of an invention, in one way or the other acquiring or circumventing intellectual property rights or taking advantage that no such protection was in place. However, later in the process of commercialising innovation, the imitator in fact becomes a pioneer. It tries to solve a task nobody has undertaken before, namely, it tries to transform what has been a rather unpopular product so far into one that is in demand on the market.

Another stage in this evolution entails a consolidation wave. Here, market competition produces the winner out of a number of diverse product versions. This is the precisely the situation described by Friedrich Hayek who defined competition as a discovery procedure. The number of firms and product variants is getting smaller, very quickly at first, and then 
more slowly and gradually, over a longer period. Ultimately, a specific/concrete product variant from one firm, or a small number of firms, becomes the "primary" one and starts to define its market.

The specific product model which defines the market and a narrow class of products that are put on it is described as the dominant model and its creation is a decisive event in the development of a mature market. Market players whose product underpins this dominant model gain sustainable competitive advantages, and although they are often copycats who only offer some specific product enhancements, they make a decisive contribution to market success and strengthen their reputation.

To give an example, the event that kicked off the consolidation process in the automotive industry was the launch of the Ford Model T. Importantly, H. Ford did not invent the car or the assembly line mode of production. Yet, for the public, he is the father of the automotive industry, having successfully combined the two inventions and creating the marketdominant Ford Model T.

This is actually the stage where inter-model competition transitions into one involving various variants of the same model. Companies derive their specific versions from the base product, adding to it the features which their customers have found most to their liking. This leads to the market becoming less diverse compared with the time before the dominant model was launched. The imitators' further results at this stage become more canonical, which is an explicit consequence of the original-derived copying process.

While the products will differ from one another, those are not fundamental differences, facilitating comparisons. In their choice of one product over the others, consumers are guided primarily by the price-to-quality consideration. The most salient factor is that, once the dominant model is out there, new customers find it easier, and are more willing, to enter the market. An eccentric experimenter, who is willing to try out at his own risk something new that nobody else knows, is replaced by a reasonable client/consumer who knows precisely what product they are ready to buy, for what purpose, and at what maximum price. This is exactly the development that transforms what was initially a fragmented niche-based market into an established mass market in its own right.

Now comes the stage of evolution when groundbreaking innovations become incremental or develop gradually. Many innovations improve upon or develop the already existing products or services, allowing them to be used as before but with better effect. These gradual innovations are essentially creative imitations.

Phased innovations are determined by demand. They are usually designed to develop or expand the existing markets. Innovations of this kind usually take the form of product development or manufacturing process renewal and despite the benefits that could bring, they do not create new markets. The volume of demand may help determine which innovations will be successful on the market and which ones will end in failure.

One essential feature of creative imitations that occur in the gradual innovation process is their complex nature. Gradual innovation sees a number of product characteristics being improved simultaneously. At the same time, the product should remain within the appropriate price bracket and, as such, be manufactured at a low enough cost level. In effect, 
gradual innovation is not just about the product itself, but also about its manufacturing technology. Generally, therefore, only large companies that lead the market can handle the task of complex and gradual product improvements. This points to a correlation between the size of the company and the effectiveness of its imitation strategy.

The time of market launch is therefore crucially important in executing the strategy of imitation. There is a perception that an imitator should act as quickly as possible so that it necessarily comes in second after the pioneer. As a matter of fact, the situation is significantly more complex than that and depends to a large extent on a stage in the product's life cycle and the nature of imitation itself. It is often the case that a pioneer will launch its innovation long before the established market starts showing a high growth rate. In such a case, should the imitator enter the market right after the first mover did, it will also - like the pioneer - be bogged down in what is a yet-undeveloped customer base, unable to benefit from its imitation.

Contrasting with it is a potential 'tardy imitator' situation. Here, it will be only the pioneer and the first imitators that will benefit from producing the innovation. The main group of followers enters the market when everybody already knows that the product to be copied has good prospects. As a result, there will be too many wanting to produce 'certain' innovations, effectively leading to overproduction and price wars. For that reason, the imitator should not enter the market right after the first-mover, and not when the market is maturing, but at a time when it shows the highest growth potential. It is also necessary that the imitator too has competitive advantages to strengthen its position on a growing market.

\section{Competitive Processes in New Product Evolution}

In order to treat imitation as something correct and part of the strategy, flexibility, openness and acceptance of changes are necessary (Henderson \& Clark, 1999, pp. 9-30), however, there is an important obstacle in this regard - prejudice.

The literature describes a number of imitation strategies. While this somewhat of a simplification, they could be divided into four groups.

\subsection{Price Advantage. Imitators Who Follow this Strategy Rely on Two Courses of Action}

- They offer copies of an innovative product at the most affordable price possible;

- They offer a stripped-down product version at a much lower price than that offered by the pioneer (Schnaars, 2004, p. 211).

What is common to these two price strategies is that imitators seek those customers who want to use an innovative product but are not willing to pay the price at which the pioneer sells it. That said, they are not identical.

In the first variant, the strategy simply draws on what was already described as the main source of the imitator's low prices - its low costs. The lower R\&D costs can lead to lower prices. It is estimated that the imitators' costs are $35-40 \%$ lower than those of innovators (Shenkar, 2010, p. 9). This difference in costs is what makes it possible to offer reduced prices or (at a given price level) provide a better quality product, distribution or maintenance 
service, a longer warranty, or more financing for technological improvements. In addition to R\&D spending, imitators can also save on promotion: unlike the pioneers, they do not have to pay for new product placement. Once the customers make their purchase drawn in by the innovator's advertising campaigns and see the advantages of the innovation, they can easily change their choice later on and start buying a cheaper copy of what they believe is the product with the same features as the original.

In its second variant, the low-pricing strategy is also based on the imitator's lower costs compared to those of the pioneer. However, there is an extra factor at play here: the imitator makes a deliberate decision to drop some functionalities of the innovation in order to bring it to a lower price class.

\subsection{Product Advantage}

In most cases, markets formed through radical innovation allow for a 'copy and improve' strategy to be employed. It is seldom the case that the pioneer gets everything right from the start. They are unable to predict exactly the direction in which the technology and the product market itself will develop. Even in those cases where the right solutions are found to the problems and the mass market is established, the imitator can still rely on this kind of strategy to offer a product that stands a chance to finding a certain market niche for itself. Indeed, apart from the general demand, there is diversity in demand for certain categories of products, with various customer groups requiring them to feature some specific features. More often than not, the pioneer is unable to cater to this and leaves global space for its imitators to develop.

In following the 'copy and improve' strategy, it is important that a future imovator has appropriate $R \& D$ resources. Accordingly, if imitation occurs at the time the pioneer's new product comes to market, this means that the imitator, too, had its own solutions in a specific area of production, but was unable to enter the market first. In such a case, the imitator tries to transform its weaknesses (being late in the leadership race) into strengths (taking advantage of the pioneer's mistakes). The imitator will borrow the essential features of the pioneering product and improve on it with ideas from its own products to arrive at a final version.

Another common situation is where imitation does not start when the new product is launched, but after its patent protection has expired, sometimes many years later. In this case, the "copy and improve" strategy is often targeted not just against the pioneer (or not so much against the pioneer) but also against pure imitators offering faithful product copies as part of their price advantage strategy.

The market that features both a well-placed pioneering product and its cheaper copies makes it difficult for another imitation to take root. It is inferior from the pioneer's product in terms of quality and reputation, while the cheaper copies outdo it in terms of price. The solution here might be the "copy and improve" strategy utilising the imitator's own R\&D resources. The most important thing for the imitator is to demonstrate that, in some respects, its copy is better than the original. 


\subsection{Market Position Advantage}

An imitation strategy can also rely on the imitator's market position advantage. The key feature of this strategy is that it does not seek for a product copy to stand out in terms of some characteristics (such as price or quality), but its purpose is to gain competitive advantage for the imitator's company. In practical terms, aware of its strength, the imitator just waits until innovation comes to and is embraced by the market and then just pushes the pioneer out of it. In fact, the market strength is one of the prerequisites for copycat companies to overtake the pioneers.

This does not mean that imitation will always ensure a competitive victory to large firms. It is not the imitator's size that is the more important factor, but the relationship between the imitator's size and that of the pioneering firm. The typical effects of large and small firms vying with each other might be as follows:

- A large imitator might be successful against a large pioneer, but its success will be very cost-intensive.

- A small imitator will stand a chance competing against a large pioneer primarily in niche markets.

- In most cases, a large imitator will gain dominance over a small pioneer and will determine the character of the new product's dominant model.

- Small imitators will operate on the market side by side with small pioneers until the new product's dominant model emerges.

Accordingly, a large pioneer will be rather invulnerable to attacks from its various imitators. To the extent innovation can be quickly brought to the stage where its dominant model emerges, the large pioneer has a chance of maintaining its competitive advantages over long term. If the pioneer's competitors include small copycat firms, they will have some chance of growth in niche markets (i.e. ones that the pioneer has no interest in).

The success of a large copycat firm's attack to undermine a large pioneering firm is not a foregone conclusion, either, as it involves an attempt to dethrone a market-dominant model using a product that is not much different from it. Changing product characteristics is not reasonable, given that the market has already embraced those of the new product. This means that the pioneer has on its side all the first-mover advantages, such as a well-honed product, an organised sales network, high reputation with customers, etc. In such a case, breaking through the defences will only be possible if there is a particularly strong consolidation of resources, but this rarely succeeds in practice.

The only exception to the "large pioneers are unassailable" rule, and one that is often seen in business, is where a pioneer whose patent protection has expired does not factor in the new reality it operates in and is not willing to reduce prices. Usually, this only ever happened when a large innovating company does not intend to fight for the market for its product (for example, because it holds another innovation in reserve). 


\subsection{Reducing Competitive Risk}

The foregoing strategy options are offensive in nature. In turn, the competitive risk reduction strategy is primarily defensive, and its purpose is to defend incumbent companies against a market innovator (Lieberman \& Asaba, 2016, pp. 366-385).

When used in this role, imitation is particularly effective (and therefore often employed) where innovation is incremental. When firms all take same actions, there is little chance that any one of them will get significantly ahead of others or that it will achieve inferior outcomes vis-à-vis the rest. Imitation thus helps to preserve the status quo among competitors, even when the rivalry in their sector is strong. In addition, at this point, one should also take into account the situation where the effects of imitation tend to decrease after the first market entry. (Guillen, 2017, pp. 514-515)

\section{Discussion}

Primarily, large firms have production capacity to mass produce the market-accepted innovations; additionally, they are characterised by robust marketing resources that allow them to promote their new products effectively and build their reputation. They also operate the right distribution channels they can use to sell their imitations. Finally, they have financial resources to ensure their business growth.

Small-scale pioneers are often victims of their own success. Demand for attractive innovations grows, quickly reaching the level at which small firms are unable to satisfy it. There occurs what one could term the effective innovator dilemma, which is whether to develop at a pace matching the market growth or at the innovator's natural pace, as determined by its internal resources. Therefore, Teece et al. $(1997$, p. 516) pointed out that the organization should achieve the appropriate dynamic capacity, i.e. "the firm's ability to integrate, build and reconfigure internal and external competencies to address rapidly changing environments" to achieve competitive advantage in range of hard-to-follow resources. (Pyle \& Liker, 2014, p. 78)

The operating assumption in the first variant is that incipient demand will be satisfied. In this case, the fast-growing market requires the pioneer to produce at an equally fast pace, which might create problems internally. There is an important problem of business financing: loans are often expensive and might be unavailable for a small firm. What is more, debt might turn out to be a mine that can explode at the first sign of falling sales, for example at the onset of a crisis. Reaching out for an outside investor in such a situation might mean loss of autonomy. In practice, acquiring a pioneer is often an alternative route to imitation strategy. From a large company's perspective, creating its own copy of the innovation or taking over the pioneering firm to gain control over the original product are alternative courses of action.

In addition to its financial problems, a pioneer that tries to keep pace with a fast-growing demand will also face the problem of quality. Very often, the cost a pioneer pays for ramping up its production output rapidly is lower quality.

It is typical of quality to drop when transitioning to mass markets. The pioneer's production processes often lack stability, personnel loyalty takes a hit (a lot of new people 
introducing the changes), maintenance service goes down in quality, and management mistakes crop up caused by insufficient experience navigating the mass market. In effect, when large imitators move in with the necessary resources and experience, they can often quite easily snatch the market share from the embattled pioneer.

The other solution to the effective innovator dilemma is for a firm to grow as its internal capabilities allow it, securing only that share of a growing demand that the pioneer is able to satisfy without overexploiting its own resources. Here, the problem of a too rapid growth, as mentioned above, will not arise, and the pioneer will essentially give up on its aspiration to lead as the producer of its own innovation. Gradually, the pioneer will become a niche manufacturer, with often expensive results of its activity. Seizing the opportunity to serve the market that is not occupied by the pioneer, a large imitator will start to dominate over it. Accordingly, an essential feature of the competition process is that large companies use imitation to start dominating the 'small' players as soon as the market comes a mass market.

Also, because incremental innovations are not radical, the level of information uncertainty involved is low, meaning that one can predict with precision how the market will react to whatever action is taken. There is no dilemma therefore as to which actions by competitors should be copied, and which ones should not. Essentially, copying incremental innovations is a procedure that limits the risk of an innovative competitor forging too far ahead of its competitors. The level of risk is affected in a much more complex manner by imitation in the environment of significant information uncertainty; an example could be radical innovation where company $X$ pursues some hazardous venture (betting on electrical cars being mass produced). Market players do not know whether the bet will be successful. However, for other firms in the industry to maintain their relative competitive advantages, mimicking this behaviour will be reasonable, even under conditions of risk and uncertainty.

This will allow, in the long term, going beyond the manager's routine behavior, according to the literature on the subject, to determine the moderating influence of the context on the relationship between the company's activities and the competition. (Majora et al., 2016, p. 84)

Indeed, if imitators repeat what company $X$ has done, and by that time the market has sufficiently matured for a share of electrical cars to grow significantly, imitation will prove to have been a rational choice for all the players. If the pioneer was wrong, however, and the long-heralded era of domination by electrical cars has failed to materialise, the pioneer and the imitators will be on the losing end. Importantly, though, everybody will have lost, meaning that nobody has lost relative to others, with everyone losing just as much. However, if competitors do not follow the example of company $X$, the situation will start looking like a gamble. If the market falls short on its promise, company $X$ will be the only one to suffer losses, but the other players will have won hardly anything (just one competitor losing will not change the overall industry picture). If the market does live up to its promise, though, all competitors that have chosen not to follow company $\mathrm{X}$ will incur huge losses in relative terms. This is because they have given up on what turned out to be a promising market for electrical cars and handed it to just one of them. Therefore, imitating innovation even when it is uncertain does not carry a risk to any specific firm of its competitive position becoming 
weaker. On the other hand, giving up on imitation might pose a great danger if the pioneer succeeds.

For this reason, the analysis of a specific industry should focus on the organization's business orientation and knowledge management strategy. Using the acquired knowledge based on Nonaka's knowledge creation theory, a model can be proposed that combines knowledge and an organization management strategy with the use of imitation and innovation processes. (Nguyen \& Pham, 2017, p. 86)

\section{Conclusion}

The literature on the subject (Bolton, 1993) indicates that an organization achieves a competitive advantage by using knowledge in the field of innovation and imitation. Therefore, the inherent features of any innovative strategy (innovation vs. imitation) are: 1) learning processes, 2) sources of knowledge, 3) required expenditure on research and development, 4) information and its flow. In a situation of correlation between the organization's strategy and learning abilities in the organization, an improvement in effectiveness and efficiency can be observed, and consequently an increase in the competitive advantage of the organization. (Muafi \& Uyun, 2019, p. 148)

More and more companies adopt business ideas from the outside in order to reduce costs and support the growth process, due to the adopted competition strategy. As a result, the organization of an imitation-oriented strategic management system attracts more and more attention of managers. Imitation is a typical form of activity that has emerged in various business conditions. The forms imitate each other in terms of new products or processes, in terms of implementing management systems and organizational solutions, methods of entering the market and directions of capital investments. In practice, there are many examples of companies using various imitation strategies as they strengthen their market position. As business ideas materialize, as the company grows, they go through certain stages that correspond to the nature of the imitative continuum. Initially, it may be a pure imitation of a new technology with a price competitive advantage in a given market. A creative element is gradually added as the company has the ability to meet the specific needs of the local market through innovation that complements the original product and meets specific customer specific needs. The success of the imitation strategy in the case of a small company may most often be related to the niche satisfaction of the recipient's needs. It is not without reason that companies of this type are described as conquerors of "blue oceans" (free market niches). As a result of the increase in the originality of its own ideas, the company begins to export its own products. The essence of the management strategy here lies in the fact that imitation of someone else's experience and own innovative activity are not alternative but mutually reinforcing processes.

\section{References}

Bayus, B. L., Erickson, G., \& Jacobson, R. (2003). The Financial Rewards of New Product Introductions in the Personal Computer Industry. Management Science, 49(2), 197-210.

https://doi.org/10.1287/mnsc.49.2.197.12741 
Bolton, M. K. (1993). Imitation versus innovation: Lessons to be learned from the Japanese. Organizational Dynamics, 21(3), 30-45. https://doi.org/10.1016/0090-2616(93)90069-D

Drucker, P. F. (2008). The Essential Drucker: The Best of Sixty Years of Peter Drucker's Essential Writings on Management. Harper Collins.

Ethiraj, S. K., \& Zhu, D. H. (2008). Performance effects of imitative entry. Strategic Management Journal, 29(8), 797-817. https://doi.org/10.1002/smj.696

Guillen, M. F. (2002). Structural Inertia, Imitation, and Foreign Expansion: South Korean Firms and Business Groups in China, 1987-1995. Academy of Management Journal, 45(3), 509-525. https://doi.org/10.5465/3069378

Henderson, R. M., \& Clark, K. B. (1990). Architectural Innovation: The Reconfiguration of Existing Product Technologies and the Failure of Established Firms. Administrative Science Quarterly, 35(1), 9. https://doi.org/10.2307/2393549

Jalagat, R. (2016). The Impact of Change and Change Management in Achieving Corporate Goals and Objectives: Organizational Perspective. International Journal of Science and Research (IJSR), 5(11), 1233-1239.

Kirzner, I. M. (2009). The alert and creative entrepreneur: a clarification. Small Business Economics, 32(2), $145-152$. https://doi.org/10.1007/s11187-008-9153-7

Kirzner, I. M. (2010). Konkurencyjność i przedsiębiorczość. Fijorr Publishing.

Krzakiewicz, K., \& Cyfert, S. (2016a). Innovation in shaping dynamic capabilities of organizations. Management, 20(2), 8-22. https://doi.org/10.1515/manment-2015-0047

Krzakiewicz, K., \& Cyfert, S. (2016b). Imitacja w epoce innowacji - dylemat i paradoks współczesnego zarządzania. Prace Naukowe Uniwersytetu Ekonomicznego We Wrocławiu, 420. https://doi.org/10.15611/pn.2016.420.16

Krzakiewicz, K., \& Cyfert, S. (2017). Strategie imitacji w procesie budowy przewagi konkurencyjnej. In A. Sopińska, \& P. Wachowiak (Eds.), Wyzwania współczesnego zarządzania strategicznego (pp. 211-228). SGH Publishing House Warszawa.

Krzakiewicz, K., \& Cyfert, S. (2018a). Potential for imitation as a dynamic capability of organisation. Management, 22(1), 1-10. https://doi.org/10.2478/manment-2018-0001

Krzakiewicz, K., \& Cyfert, S. (2018b). Strategiczne aspekty dynamicznych zdolności replikacji i imitacji wiedzy. Przeglad Organizacji, 3, 5-12. https://doi.org/10.33141/po.2018.03.01

Krzakiewicz, K., \& Cyfert, S. (2019). Imitation strategies within the framework of dynamic capabilities. In K. Krzakiewicz, \& S. Cyfert (Eds.), Dynamic capabilities and their strategic dimension. Aspects of imitation and innovation (pp. 52-63). Poznań University of Economics and Business.

Levitt, T. (Ed). (2006). Ted Levitt on Marketing. A Harvard Business School Pub.

Lieberman, M. B., \& Asaba, S. (2006). Why Do Firms Imitate Each Other? Academy of Management Review, 31(2), 366-385. https://doi.org/10.5465/amr.2006.20208686

Major, D. L., Maggitti, P. G., Smith, K. G., Grimm, C. M., \& Derfus, P. J. (2016). Reflexive and Selective Competitive Behaviors - Inertia, Imitation, and Interfirm Rivalry. Organization Management Journal, 13(2), 72-88. https://doi.org/10.1080/15416518.2016.1179564

Muafi, \& Uyun, Q. (2019). Imitation vs Innovation: Is there an alignment between supply chain organizational learning and Islamic HRM practices? HOLISTICA - Journal of Business and Public Administration, 10(3), 143-156. https://doi.org/10.2478/hjbpa-2019-0034

Nguyen, V. T., \& Pham T. A. (2017). Knowledge Management Strategies, Imitation, and Innovation: An Empirical Study of Vietnamese Firms. In J. Hong, R. S. Snell, \& C. Rowley (Eds.), Organizational Learning in Asia. Issues and Challenges (pp. 85-107). Elsevier. https://doi.org/10.1016/B978-0-08-100983-3.00004-6

Pyle, M. J., \& Liker, J. K. (2014). Imitation in Large Complex Organizations: A Case of Design for Six Sigma in the Automobile Industry. Journal of Enterprise Transformation, 4(2), 76-99. https://doi.org/10.1080/19488289.2013.823897

Schnaars, S. P. (1994). Managing imitation strategies: how later entrants seize markets from pioneers. Free Prezz.

Shenkar, O. (2010). Copycats: how smart companies use imitation to gain a strategic edge. Strategic Direction, 26(10), 3-5. https://doi.org/10.1108/02580541011080474

Teece, D. J., Pisano, G., \& Shuen, A. (1997). Dynamic Capabilities and Strategic Management. Strategic Management Journal, 18(7), 509-533. 